\title{
Postprandial plasma 5-hydroxytryptamine in diarrhoea predominant irritable bowel syndrome: a pilot study
}

\author{
C P Bearcroft, D Perrett, M J G Farthing
}

\begin{abstract}
Background-Increased concentrations of 5-hydroxytryptamine (5-HT) can be detected in the systemic circulation after a meal and may be involved in the physiological control of gastrointestinal motility. Abnormalities of 5-HT release after a meal might explain some of the postprandial symptoms associated with the irritable bowel syndrome (IBS).

Aim-To investigate the effect of a standard meal on plasma 5-HT and urinary 5-hydroxyindole acetic acid (5-HIAA) concentrations in patients with diarrhoea predominant IBS and in healthy volunteers.

Methods-After an overnight fast, six volunteers and five patients with IBS were given a carbohydrate-rich meal. Blood and urine samples were taken before and for four hours after the meal. Plateletpoor plasma 5-HT and urinary 5-HIAA were analysed by reversed phase high performance liquid chromatography with fluorometric detection. 5-HIAA was expressed as a ratio with urinary creatinine concentration, which was measured by spectrophotometry.
\end{abstract}

Results-During the four hour postprandial period, 5-HT concentrations were significantly higher in patients with IBS than in healthy volunteers at 0.5 hours $(p<0.05), 2$ hours $(p<0.05)$ and 2.5 hours $(p<0.05)$. 5-HT was not detected in the plasma in the fasting state in patients or volunteers. Median peak 5-HT in patients with IBS (359 (198-796) $\mathrm{nmol} / \mathrm{l})$ was significantly greater than volunteers $(83$ $(7-190))(p<0.05)$. "Area under the curve" for 5-HT detection was greater for patients with IBS (317 (138-771)) than for healthy volunteers (51 (4-129); $p<0.05)$. The duration of the 5-HT peak was significantly longer in patients with IBS (3 (1-3) hours) than in the healthy volunteers (1 (1-1) hours; $p<0.01)$. Postprandial urinary median 5-HIAA values in controls $(5.6(5.5-5.8) \mu \mathrm{mol} / \mathrm{mmol}$ creatinine) and patients with IBS (3.0 (2.56.8) $\mu \mathrm{mol} / \mathrm{mmol}$ creatinine) were not significantly different from preprandial values (controls: 5.9 (5.5-6.6) $\mu \mathrm{mol} / \mathrm{mmol}$ creatinine; patients with IBS: (6.2 (2.49.3) $\mu \mathrm{mol} / \mathrm{mmol}$ creatinine).

Conclusion-These findings indicate that there may be a difference in the way that 5-HT is released in patients with diar- rhoea predominant IBS, and could suggest a possible role for 5-HT in the postprandial symptoms of these patients. (Gut 1998;42:42-46)

Keywords: 5-hydroxytryptamine; postprandial; diarrhoea predominant irritable bowel syndrome

Irritable bowel syndrome (IBS) is associated with accelerated gastrointestinal transit, ${ }^{1}$ a variety of manometric abnormalities in the small and large intestine, ${ }^{2}$ increased visceral sensation, ${ }^{3}$ and psychological features, including depression and anxiety. ${ }^{4}$ The aetiology of IBS is uncertain, but 5-hydroxytryptamine (5-HT) may be involved.

5-Hydroxytryptamine is found throughout the gastrointestinal tract, located predominantly in enterochromaffin cells but also in the enteric nervous system, where it accounts for $80 \%$ of total body $5-\mathrm{HT}$. Virtually all of the $5-\mathrm{HT}$ in the blood is derived from the gastrointestinal tract, ${ }^{67}$ and platelets have an avid uptake system to extract 5-HT from plasma and store it in dense granules. ${ }^{8}$ In the kidney and the liver, the enzymes monoamine oxidase and aldehyde dehydrogenase convert 5-HT to 5-hydroxyindole acetic acid (5-HIAA) which is excreted in the urine.

5-Hydroxytryptamine has been shown to be involved in controlling the migrating motor complex, ${ }^{9}$ initiating peristalsis, ${ }^{10}$ and in healthy volunteers the 5-HT re-uptake inhibitor paroxetine reduced orocaecal transit time. ${ }^{11} 5-\mathrm{HT}$ has been shown to stimulate colonic function and the 5- $\mathrm{HT}_{3}$ receptor antagonist ondansetron slows colonic transit in healthy humans ${ }^{12}$ and inhibits the tonic component of the gastrocolonic response in humans. ${ }^{13}$ 5-HT also induces intestinal secretion of fluid and electrolytes in animal models and isolated tissue preparations. ${ }^{14}{ }^{15}$ The secretory diarrhoea of carcinoid syndrome, which is associated with increased plasma 5-HT and urinary 5-HIAA concentrations, ${ }^{16}$ is alleviated by $5-\mathrm{HT}_{3}$ receptor antagonism with tropisetron in some patients. ${ }^{17}$ The $5-\mathrm{HT}_{3}$ receptor antagonist ondansetron reduces the postprandial colonic hypertonic response in patients with carcinoid syndrome. ${ }^{18}$

There are parallels between the features of IBS, such as diarrhoea, increased gastrointestinal transit $^{1}$ and small intestinal secretion, ${ }^{19}$ and the effect of 5-HT on motility $^{13} 20$ and in animal models as a secretagogue. ${ }^{14}$ A link between 5 -HT and IBS may also be suggested by the finding of an
Accepted for publication 31 July 1997 

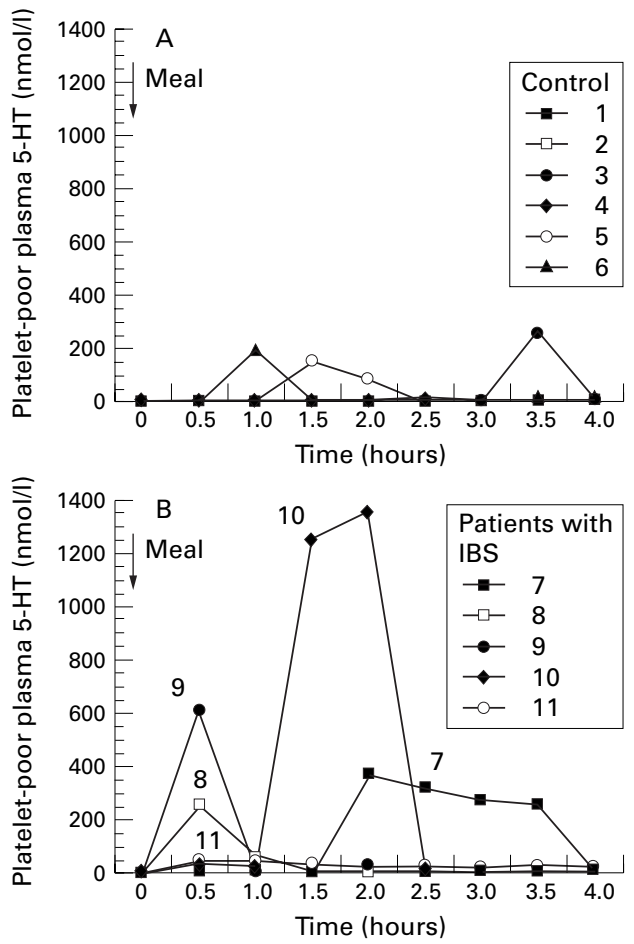

Figure 1 (A) Postprandial 5-HT profiles in patients with diarrhoea predominant IBS after a meal at zero hours. (B) Postprandial 5-HT profiles in healthy volunteers after a meal at zero hours.

increased number of enterochromaffin cells on rectal biopsy. ${ }^{21}$ 5- $\mathrm{HT}_{3}$ receptor blockade reduces rectal hypersensitivity in patients with IBS $^{22}$ and some symptoms of IBS (for example, stool consistency) may also be ameliorated by $5-\mathrm{HT}_{3}$ receptor antagonism. ${ }^{123}$

In order to try to determine further whether there may be a role for 5-HT in IBS we investigated the effect of a meal on platelet-poor plasma 5-HT and urinary 5-HIAA concentrations in patients with diarrhoea predominant IBS in comparison with healthy controls, as postprandial release of 5-HT into plasma had been shown previously in healthy volunteers. ${ }^{24}$

\section{Materials and methods}

SUBJECTS

Six healthy volunteers (median (range) age 26 (18-32) years; one woman, subject 3) and five patients (33 (18-54) years; all women; median (interquartile range) duration of symptoms 4.0 (0.7-9.2) years) with diarrhoea predominant IBS were enrolled in the study. IBS was diagnosed by standard criteria, ${ }^{25}$ and all patients had been attending the gastroenterology outpatient department at St Bartholomew's Hospital, London. None of the patients or volunteers were on any medication at the time of the study. Volunteers and patients gave informed consent. The study was approved by the City and Hackney Health District Research Ethics Committee.

MEAL COMPOSITION AND 5-HT ANALYSIS

Following an overnight fast, venous blood samples were taken from the volunteers and patients with IBS 60 and 30 minutes before ingestion of a carbohydrate-rich meal. The meal was eaten over 10 minutes and consisted of two slices of white bread ( $30 \mathrm{~g}$ each) topped with $15 \mathrm{~g}$ jam (total $200 \mathrm{kcal}$, carbohydrate $85 \%$, protein $12 \%$, fat $<0.8 \%$ ). A similar meal had been shown previously to induce a postprandial rise in plasma $5-\mathrm{HT}^{24}$ Venous blood $(10 \mathrm{ml})$ was collected into tubes containing EDTA every 30 minutes for four hours after the meal. To obtain platelet-poor plasma, blood samples were immediately centrifuged at $5000 \mathrm{~g}, 4^{\circ} \mathrm{C}$ for 10 minutes before the platelet-poor plasma supernatant was aspirated and stored at $-20^{\circ} \mathrm{C}$ before analysis of 5-HT by high performance liquid chromatography (HPLC). During validation of the method, the intra-assay reproducibility in pooled plasma was $2.5 \% \quad(n=9)$ and mean recovery performed at $0.2 \mu \mathrm{M}$ final concentration of 5-HT in "old" plasma which had lost its endogenous 5 -HT was $107.9 \%$, coefficient of variation $7.5 \%(n=8) .{ }^{26}$ The limit of quantitative detection of 5-HT and 5-HIAA was 3.5 $\mathrm{nmol} / 1$ and the mean (SEM) platelet count of the plasma after centrifugation was $3.4(0.5) \times$ $10^{9} / 1$.

URINE

Urine collections were made before the meal (after first voiding of the day) and at the end of the experiment. Urinary 5-HIAA was analysed by reversed phase HPLC with fluorometric detection. ${ }^{26}$ During validation of the method the intra-assay reproducibility for the method of detection of 5-HIAA was $3.38 \%(n=12)$ and mean recovery performed at $10 \mu \mathrm{M}$ final concentration was $96.3 \%(n=6) .5$-HIAA was expressed as a ratio with creatinine, which was measured by spectrophotometry (Sigma, Poole, UK).

\section{STATISTICS}

The results are expressed as median (interquartile range) and were compared by MannWhitney U test.

\section{Results}

PLATELET-POOR PLASMA 5-HT

The postprandial 5-HT release profiles for patients with IBS and volunteers are shown in fig 1. After an overnight fast, platelet-poor plasma 5-HT concentrations were undetectable in the patients with IBS and controls. The postprandial 5-HT concentration in patients with IBS was significantly higher than that in healthy volunteers at 0.5 hours $(p<0.05), 2.0$ hours $(\mathrm{p}<0.05)$, and 2.5 hours $(\mathrm{p}<0.05)$. Median peak 5-HT concentration in patients with IBS (359 (198-796) nmol/l) was significantly greater than that in volunteers (83 (71$90) ; \mathrm{p}<0.05)$. "Area under the curve" for $5-\mathrm{HT}$ detection in the plasma was also greater for patients with IBS (317 (138-771) h.nmol/l) than for healthy volunteers (51 (4-129); $\mathrm{p}<0.05$; fig 2). Postprandial 5-HT and "area under the curve" were increased in four of the five patients with IBS. The duration of 5-HT detection in all the patients with IBS (3 (1-3) hours) was greater than in healthy volunteers $(1(1-1) ; p<0.05)$. Of the patients with IBS, subjects 7 and 9 had painless diarrhoea 


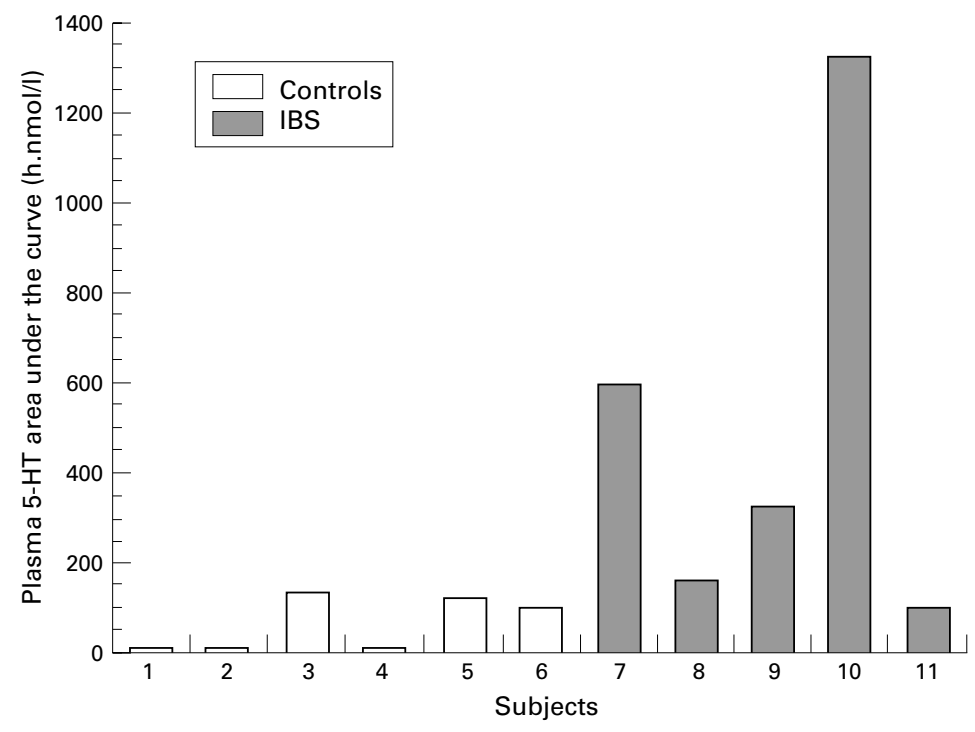

Figure 2 Plasma 5-HT "area under the curve" in patients with diarrhoea predominant IBS and healthy volunteers.
5 -HT in volunteers $(83(7-90) \mathrm{nmol} / \mathrm{l})$ in this study is similar to our previously published normal range, which was not linked with meals $(61 \pm 73 \mathrm{nmol} / 1),{ }^{26}$ when the method of analysis of 5-HT and 5-HIAA by HPLC with fluorometric detection was validated. However, the median peak postprandial 5-HT concentration in patients with IBS (359 (198-796) nmol/1), in this study is the first reported in this patient group.

For accurate measurement of plasma 5-HT concentrations, platelets must not have released any of their 5-HT into the plasma at venepuncture or during centrifugation, and platelets must be removed from centrifuged samples. ${ }^{2835}$ Most plasma 5-HT has been shown not to arise from platelet release during high speed centrifugation of whole blood when collected in tubes containing EDTA, as was the case in this study. ${ }^{28}$ We were also able to confirm that the mean (SEM) platelet counts in our plasma samples were very low (3.4 (0.5) $\left.\times 10^{9} / 1\right)$. The possible presence of platelets may also explain why Blum et $a^{24}$ reported higher concentrations of fasting plasma 5-HT (10$230 \mathrm{nmol} / \mathrm{l})$ and postprandial 5-HT (44.7$1028.1 \mathrm{nmol} / \mathrm{l}$ ) in volunteers. In that study a slower rate of centrifugation was used than in the present study, and the platelet count of the platelet-poor plasma was not reported. ${ }^{24}$ In whole blood, Kellum and Jaffe ${ }^{36}$ reported a postprandial 5-HT concentration of 2064 (96) nmol/1 compared with fasting values (1129 (210) $\mathrm{nmol} / \mathrm{l}$ ) and Anderson et al ${ }^{37}$ reported no rise in whole blood 5-HT concentration during one hour after a meal but no later sampling was done. Although it may be possible to measure whole blood 5-HT, it is the platelet-poor plasma which is thought to represent 5-HT, newly synthesised or released, from enterochromaffin cells. ${ }^{29}$ Whole blood 5-HT analysis has also been brought into question due to the presence of 5-HT derived from the platelets and oxidation of 5-HT by haemoglobin iron. ${ }^{26}$

The 5-HIAA results accord with previous data: $2-8 \mu \mathrm{mol} / \mathrm{mmol}$ creatinine (calculated from $\mathrm{ng} / \mu \mathrm{g}$ creatinine) in patients prior to receiving chemotherapy. ${ }^{38}$ In the present study, it is difficult to explain why 5-HIAA is found in the urine, when the platelet-poor plasma 5-HT concentrations are undetectable and that urinary 5-HIAA is unchanged when plasma 5-HT concentrations were higher in patients with IBS. However, this is not the first time that a discrepancy between plasma 5-HT and urine 5-HIAA has been found, and there is no evidence for the existence of a linear relation between amount of gastrointestinal 5-HT released and increases in urinary excretion of 5-HIAA. From the chemotherapy literature, high dose cisplatin $\left(\geqslant 50 \mathrm{mg} / \mathrm{m}^{2}\right)$ leads to a notable increase in urinary 5-HIAA without changes in platelet or plasma 5-HT, which is explained as cisplatin induced release of 5-HT from the enterochromaffin cells of the gut. ${ }^{39}$ In patients treated with low dose cisplatin $(\leqslant 40$ $\mathrm{mg} / \mathrm{m}^{2}$ ) there is no increase in urinary 5-HIAA which is explained as due to only a small release in $5-\mathrm{HT}^{40}$ However, there may not necessarily be an exact parallel between the $\mathrm{nmol} / \mathrm{1}^{33}$ by radioenzymatic assay 0.10 $\mathrm{nmol} / \mathrm{l}$ (calculated from $\mathrm{ng} / \mathrm{ml}$ ). ${ }^{34}$ In patients with carcinoid, fasting platelet-poor 5-HT was $13.51 \pm 2.77 \mathrm{nmol} / 1$ (calculated from $\mathrm{ng} / \mathrm{ml}$ ). ${ }^{34}$ Postprandial median peak platelet-poor plasma 
5-HT-emesis theory in which cisplatin induced 5-HT is released locally in the gastrointestinal mucosa to act on $5-\mathrm{HT}_{3}$ receptors on the vagal afferents, ${ }^{41}$ and increased plasma $5-\mathrm{HT}$ in the patients with IBS in this study who had diarrhoea but no emesis. In this study the most likely source of postprandial 5-HT in the blood and 5-HIAA in the urine is the enterochromaffin cells of the gut. ${ }^{67}$ The explanation for why the fasting platelet-poor plasma $5-\mathrm{HT}$ was undetectable is possibly that the platelets, with their avid uptake system for $5-\mathrm{HT}^{8}$ may have cleared or almost cleared the plasma of 5-HT. In the postprandial state 5-HT, probably also from enterochromaffin cells of the gut, is present in the plasma which, possibly with platelet $5-\mathrm{HT}$, could then be metabolised to 5-HIAA to be excreted in the urine. If the nanomolar concentrations of 5-HT, which we were measuring in the plasma, were making an impact on the micromolar concentrations of 5-HIAA present in the urine, we were not surprised that we were unable to detect it.

Whether the postprandial plasma $5-\mathrm{HT}$ is causing the symptoms of "diarrhoea" as a result of an effect on motility or intestinal fluid and electrolyte movement, or whether the "diarrhoea" is leading to increased 5-HT release cannot be answered from this study. Alternatively, there is a theoretical possibility that non-specific factors in patients with diarrhoea predominant IBS, such as postprandial plasma osmolarity, glucose concentrations or circulating hormones, could alter platelet fragility and 5-HT release from platelets, although normal platelets have been shown not to release 5-HT during high speed centrifugation. $^{28}$ Accelerated gastrointestinal transit through the small bowel, the whole bowel $^{42}$ and through the proximal colon has been shown in diarrhoea predominant IBS. ${ }^{1}$ Although rarely discussed, there is also evidence of small intestinal epithelial secretion in patients with diarrhoea predominant IBS compared with controls. ${ }^{19}$ Several studies have suggested that $5-\mathrm{HT}_{3}$ receptor antagonists may be useful in the treatment of some patients with functional bowel disorders. There have been consistent reports of a change in human volunteer lower bowel function with selective $5-\mathrm{HT}_{3}$ receptor antagonists, including mild constipation and colonic stasis, ${ }^{12}{ }^{43}$ which has also been shown in guinea pigs. ${ }^{44}$ Prior and Read $^{22}$ reported that the $5-\mathrm{HT}_{3}$ antagonist granisetron reduced rectal motility and sensitivity to balloon distension in patients with IBS and Talley et $a l^{12}$ and Steadman et al ${ }^{23}$ showed improved stool consistency with the 5- $\mathrm{HT}_{3}$ antagonist ondansetron in patients with diarrhoea predominant IBS.

In summary, we have shown that patients with diarrhoea predominant IBS have significantly higher postprandial 5-HT concentrations and a longer duration of 5-HT peak than healthy volunteers. It is therefore possible, theoretically at least, that 5-HT could be involved in some aspects of the symptomatology of diarrhoea predominant IBS.
CPB was supported by an Alimentary Pharmacology and Therapeutics Trust/British Digestive Foundation Fellowship.

1 Vassallo M, Camilleri M, Phillips SF, et al. Transit through the proximal colon influences stool weight in the irritable bowel syndrome. Gastroenterology 1992; 102:102-8.

2 Gorard DA, Libby GW, Farthing MJG. Ambulatory small intestinal motility in 'diarrhoea' predominant irritable bowel syndrome. Gut 1994;35:203-10

3 Cook IJ, van Eeden A, Collins SM. Patients with irritable bowel syndrome have greater pain tolerance than normal subjects. Gastroenterology 1987;93:727-33.

4 Gomborone JE, Dewsnap PA, Libby GW, et al. Abnormal illness attitudes in patients with irritable bowel syndrome. $\mathcal{F}$ Psychosomatic Res 1995;39:227-30.

5 Palmer RL, Stonehill E, Crisp AH, et al. Psychological characteristics of patients with the irritable bowel syndrome. Postgrad Med F 1974;50:416-9.

6 Bertaccini G. Tissue 5-hydroxytryptamine and urinary 5-hydroxyindoleacetic acid after partial or total removal of the gastrointestinal tract in the rat. $\mathcal{F}$ Physiol (Lond) 1960;153:239-49.

7 Erspamer V, Testini A. Observations on the release and turnover rate of 5-hydroxytryptamine in the gastrointestinal tract. F Pharm Pharmacol 1959;11:618-23.

$8 \mathrm{Da}$ Prada M, Tranzer JP, Pletscher A. Storage of 5-hydroxytryptamine in human blood platelets. Experimentia $1972 ; 28: 1328-9$.

9 Davidson HI, Pilot MA. Does endogenous neuronal 5-hydroxytryptamine influence canine intestinal motility 5-hydroxytryptamine influence canine in

10 Bulbring E, Crema A. Observations concerning the action of 5-hydroxytryptamine on the peristaltic reflex. Br f Phar-
of of 5-hydroxytryptamine

11 Gorard DA, Libby GW, Farthing MJG. 5-Hydroxytryptamine and human small intestinal motility: effect of inhibiting 5-hydroxytryptamine reuptake. Gut 1994;35: 496-500.

12 Talley NJ, Phillips SF, Haddad A, et al. GR38032F (Ondansetron), a selective 5-HT3 receptor antagonist, slows colonic transit in healthy man. Dig Dis Sci 1990;35:477-80.

13 Scolapio JS, Camilleri M, von der Ohe MR, Hanson RB. Ascending colon response to feeding: evidence for a 5-hydroxytryptamine-3 mechanism. Scand 7 Gastroenterol 1995;30:562-7.

14 Beubler E, Bukhave K, Rask-Madsen J. Significance of calcium for the prostaglandin E2-mediated secretory response to 5-hydroxytryptamine in the small intestine. Gastroenterto 5-hydroxytryptamin
ology 1986;90:1972-7.

15 Donowitz M, Asarkof N, Pike G. Calcium dependence of serotonin-induced changes in rabbit ileal electrolyte transport. F Clin Invest 1980;66:341-52.

16 Feldman JM. Carcinoid tumours and syndrome. Semin Oncol 1987;14:237-46.

17 Anderson JV, Coupe MO, Morris JA, et al. Remission of symptoms in carcinoid syndrome with a new 5-hydroxytryptamine $M$ receptor antagonist. BMF 1987; 294:1129.

18 Von der Ohe MR, Camilleri M, Kvols LK. A 5-HT 3 antagonist corrects the postprandial colonic hypertonic response in carcinoid diarrhoea. Gastroenterology 1994;106:1184-9.

19 Oddsson E, Rask- Madson J, Krag E. A secretory epithelium of the small intestine with increased sensitivity to bile acids in irritable bowel syndrome associated with diarrhoea. in irritable bowel syndrome associated

20 Martensson HG, Zinner MJ, Jaffe BM. Effects of intraluminal perfusion with serotonin on jejunal motility. Dig Dis Sci 1986;31:811-6.

21 Ahonen A, Kyosola K, Penttila O. Enterochromaffin cells and macrophages in ulcerative colitis and irritable colon. Ann Clin Res 1976;8:1-7.

22 Prior A, Read NW. Reduction of rectal sensitivity and postprandial motility by granisetron, a 5- $\mathrm{HT}_{3}$ receptor antagonist in patients with irritable bowel syndrome. Aliment Pharmacol Ther 1993;7:175-80.

23 Steadman CJ, Talley NJ, Phillips NS, Zinsmeister AR. Selective 5-hydroxytryptamine type 3 receptor antagonism with ondansetron as treatment for diarrhoea-predominant irritable bowel syndrome: a pilot study. Mayo Clinic Proc 1992;67:732-8

24 Blum I, Vered Y. Graff E, et al. The influence of meal composition on plasma serotonin and norepinephrine concenposition on plasma serotonin and norep
trations. Metabolism 1992;41:137-40.

25 Manning AP, Thompson WG, Heaton KW, Morris AF. Towards a positive diagnosis of the irritable bowel. BMF Towards a positive
$1978 ; 2: 653-4$.

26 Bearcroft CP, Farthing MJG, Perrett D. Determination of 5-hydroxytryptamine, 5-hydroxyindoleacetic acid and tryptophan in plasma and urine by HPLC with fluorimetric detection. Biomed Chromatography 1995;9:23-7.

27 Chaudhary NA, Truelove SC. The irritable colon syndrome: a study of the clinical features, predisposing causes, and prognosis in 130 cases. Q $\mathcal{F} M e d$ 1962;31:30722 .

28 Anderson GM, Feibel FC, Cohen DJ. Determination of serotonin in whole blood, platelet-rich plasma, plateletpoor plasma and plasma ultrafiltrate. Life Sci 1987;40: poor plasma

29 Artigas F, Sarrias MJ, Martinez E, Gelpi E. Serotonin in body fluids: characterisation of human plasmatic and method. Life Sci 1985;37:441-7. 
30 Flachaire E, Beney C, Berthier A, et al. Determination of reference values for serotonin concentration in platelets of healthy newborns, children, adults, and elderly subjects by 2117-20.

31 Badcock NR, Spence M, Stern LM. Blood serotonin levels in adults, autistic and nonautistic children-with a comparison of different methodologies. Ann Clin Biochem 1987;24:625-34

32 Barnes NM, Ge J, Jones WG, et al. Cisplatin induced emesis: preliminary results indicative of changes in plasm levels of 5-hydroxytryptamine. Br 7 Cancer 1990;62:862-4

33 Tagari PC, Boullin DJ, Davies CL. Simplified determination of serotonin in plasma by liquid chromatography with electrochemical detection. Clin Chem 1984;30:131-5.

34 Matuchansky C, Launay J-M. Serotonin, catecholamines, and spontaneous midgut carcinoid flush: plasma studies from flushing and nonflushing sites. Gastroenterology 1995; 108:743-51.

35 Beck O, Wallen NH, Broijersen A, et al. On the accurate determination of serotonin in human plasma. Biochem Biophys Res Commun 1993;196:260-6.

36 Kellum JM, Jaffe BM. Validation and application of a radioimmunoassay for serotonin. Gastroenterology 1976;70:51622.

37 Anderson GM, Feibel FC, Wetlaufer LA, et al. Effect of a meal on human whole blood serotonin. Gastroenterology 1985;88:86-9.
38 Cubeddu LX, Hoffmann IS, Fuenmayor NT, Finn AL. Efficacy of ondansetron $(\mathrm{GR} 38032 \mathrm{~F})$ and the role of serotonin in cisplatin-induced nausea and vomiting. $N$ Engl $\mathcal{f} \mathrm{Med}$ 1990;322:810-6.

39 Cubeddu LX, Hoffmann IS, Fuenmayor NT, Malave JJ. Changes in serotonin metabolism in cancer patients: its relationship to nausea and vomiting induced by chemotherapeutic drugs. Br $\mathcal{F}$ Cancer 1992;66:198-203.

40 Cubeddu LX, Hoffmann IS. Participation of serotonin on early and delayed emesis induced by initial and subsequent cycles of cisplatinum-based chemotherapy: effects of antiemetics. F Clin Pharmacol 1993;33:691-7.

41 Andrews PLR, Rapeport W, Sanger G. Neuropharmacology of emesis induced by anticancer therapy. Trends Pharmacol Sci 1988;9:334-41.

42 Cann PA, Read NW, Brown C, et al. Irritable bowel syndrome: relationship of disorders in the transit of a single solid meal to symptom patterns. Gut 1983;24:405-11.

43 Gore S, Gilmore IT, Haigh CG, et al. Colonic transit in man is slowed by ondansetron (GR38032F), a selective 5-hydroxytryptamine receptor (type 3) antagonist. Aliment Pharmacol Ther 1990;4:139-44.

44 Sanger GJ, Wardle KA, Shapcott S. Yee KF. Constipation evoked by $5-\mathrm{HT}_{3}$ receptor antagonists. In: Fozard JR, Saxena PR, eds. Serotonin: molecular biology, receptors and functional effects. Basel: Birkhauser Verlag, 1991:381-8. 